himself in promoting is now, if not achieved, at any rate acknowledged as a necessity for a civilized community; and at a deeper level the scientific and rational attitude which was the mainspring of his life and work is nominally at least part of the intellectual climate of our time.

But it would be a very superficial view of Huxley that dismissed him as a thinker from whom we have nothing to learn. Huxley was a man who was very characteristic of his time; it can truly be said that he embodied those qualities of the Victorian Age which we can most envy and most admire. It was an age of principles and of beliefs, and Huxley himself believed passionately in the value of human reason, in the power of education to transform societies, and in the power of science to change not only man's environment but also his habits of thought. He was a Victorian of the same mould as Thomas Arnold and George Eliot. To the causes in which he believed he sacrificed his own scientific achievement, and it is an interesting speculation as one reads this book to ask whether or not Huxley was right to leave undone the original work he might have carried out in the laboratory and instead spend endless hours in committees, on the London School Board or in writing controversial articles. For him education, science and greater social equality were causes to be fought for with incredible industry, with the resources of a superb gift of writing, and with a pervading moral earnestness. If one adds to these no little ability in the art of wire-pulling for good causes one can understand why he attained an influence over the thought of his time that few men have had.

By comparison our own age seems half-hearted and disillusioned. Two great wars have shown us that a civilization highly developed in science and technology is still capable of behaving as irrationally and cruelly as a band of savages. One of Huxley's own gifted grandsons has revealed the kind of Utopia to which scientific progress can conceivably lead. We have lost the certainties and the simplicities of the Victorians, and it would no longer seem worth while for an eminent man of science to conduct a controversy with a prime minister on the credibility of the story of the Gadarene swine. The irrationalities of our time are more pervasive and infinitely more harmful than those against which Huxley fought. But if Huxley's beliefs seem in some ways over-simple, his vigour, his humanity, his belief that the scientist must show concern for the social and intellectual problems of his time, offer us a great example. Huxley stands as evidence of the fact that a scientist can also be a humanist and an educator, and Dr. Bibby deserves our gratitude for making clear this triple contribution at a time when some such synthesis is so necessary.

JAMES of Rusholme

\section{STARS AND MEN}

\section{Of Stars and Men}

The Human Response to an Expanding Universe By Harlow Shapley. Pp. vii +145. (London: Elek Books, Ltd., 1958.) 15s. net.

R. HARLOW SHAPLEY, director of the Harvard College Observatory for more than thirty years, is a world-renowned figure in the fields of astronomy and cosmography. $\mathrm{He}$ has the not common gift of being able to write simply and lucidly for both scientist and layman. Dr. Shapley begins by attempting an obituary of the anthropocentric view that man is the centre of the cosmos, and continues by interpreting the consequences to man (or rather to certain aspects of rational thinking) of the latest scientific discoveries in the cosmos. Dr. Shapley's interpretation of man's position in the cosmos-a favourite theme since the writing of the first chapter of Genesis--is the latest and the best to date, but it will not prove to be the last. No doubt Dr. Shapley deduces from our cosmological knowledge the best interpretation of our present generalizations, but only from the physical point of view. It is difficult to know how terrestrial man can ever do more than speculate on the existence of life on planets outside his own solar system. Interesting as all this is as a rational and speculative exercise, much of the issue is evaded. The nature of man as a spiritual being capable of high aspirations, of selfsacrifice, and the creation and appreciation of beautiful things, does not appear in Dr. Shapley's picture to any great extent. This is not to belittle this book; within the framework which he honestly sets out at the beginning he has developed his story with logic, restraint and charm, but few people will think that it is the whole story.

Dr. Shapley's displacement of human life from its once supreme position does not make him a pessimist, for he argues cogently that there must be at least a hundred million planets capable of sup. porting some form of life. Dr. Shapley concludes his book with what he calls "a Martian look" into the future. He dismisses the prospect of the Earth's collision with a star, or of wandering from its orbit and getting too near or too far away from the Sun. Nor does he envisage a biological calamity wiping out the whole human race. The real danger is man himself, who is busy perfecting the tools for performing an operation which is unlikely to be performed by natural forces.

"Fish or Homo, that is the question. Which animal type will most certainly be here 10,000 years from now, and which will more likely fall the victim of fate and folly? The answer, of course, is too obvious. The fish have been here several hundred million years; man but a few thousand. . . . But 10,000 years is a pretty long time for Homo. His structure and social manners do not make him a good insurance risk."

Much humanism is a weariness of the flesh and in the making of cosmologies there is no end, but Dr. Shapley avoids these pitfalls and has written a book which should stimulate and challenge every intelligent reader.

W. L. SUMNER

\section{ASTROPHYSICS}

Handbuch der Physik

Herausgegeben von S. Flügge. Band 50: Astrophysik 1 : Sternoberflächen-Doppelsterne. Pp. vii +458. (Berlin : Springer-Verlag, 1958.) 98 D.M.

THIS is the first of the five volumes of the new "Handbuch der Physik" which are to be devoted to astrophysics. Preliminary announcements show that a wide range of subjects is to be covered, excluding solar physics but including some of the most recent developments in other fields. However, the contributions in this particular volume deal mostly with the older parts of astrophysics, based on 